the ways in which health authorities and general practice purchasers now make their decisions, so that recommendations that are made can be translated into practice. A National Council for Health Care Priorities should draw on this information and experience from other countries in developing methods for determining priorities and monitoring how they are set while protecting training, research, and development.

LESLIE TURNBERG President

MAURICE LESSOF

Chairman of working party on priorities in health care PETER WATKINS

Honorary secretary of working party on priorities in health care

Royal College of Physicians,

London NW1 4LE

1 Royal College of Physicians. Setting priorities in the NHS: framework for decision making. London: RCP, 1995.

\section{Rationing in the NHS}

\section{Public does not always favour lifesaving, acute interventions}

EDITOR,-I recently ran a series of seven focus groups on rationing and prioritising in the NHS, which were attended by members of the general public in the Cambridge and Huntingdon area. The results provide an interesting contrast to those of previous studies, including that by Ann Bowling ${ }^{1}$ which have consistently indicated that the highest priority is attached to lifesaving, acute interventions. I found that more investment in services for mentally ill and elderly people was considered to be essential and was accorded higher priority than cancer services and high technology surgery. A shorter life of higher quality was thought preferable to painful longevity, with patients' informed choice and control over treatment being seen as essential components of "quality of life."

Participants said that they would advise the health authority to base purchasing decisions on ensuring "the greatest good for the greater number." This meant trying low technology, alternative approaches before the more costly invasive treatments, even in life threatening circumstances.

One reason for these and other differences from Ann Bowling's findings may be the methods used. The focus groups lasted two or more hours, which allowed participants to undertake several discussion exercises. This enabled them to engage with complex issues and to encounter the diversity of opinion within the group before attempting to reach a consensus on purchasing options; this is not dissimilar to what happens in real purchasing by paid professionals. Although participants recognised their lack of technical information, most thought that, given more time and information, lay people could make a positive and unique contribution to debates about the allocation of resources in the health service.

The health authority's purpose in conducting the focus groups was to begin a long, continuous process of public involvement in and education about priority setting in the health service. The exercise was not intended to serve as the basis for immediate changes to purchasing. While we are interested in people's basic instincts, we are equally interested in developing their capacity as partners in the decision making process. The challenge presented by the public's involvement is to ensure that its views are heard, valued, and acted on appropriately.

SUE HAY

Public involvement officer Cambridge and Huntingdon Health Authority, Fulbourn Hospital,

Fulbourn Hospital,

1 Bowling A. Health care rationing: the public's debate. $B M 9$ 1996;312:670-4. (16 March.)
Social decisions associated with rationing are not yet acceptable

EDITOR,-The $B M Y$ is a scientific journal, testing practice against theory and theory agains practice and thus changing both in a verifiable progress towards the solution of human problems. These problems include two questions: how much should we spend on health care and what should we spend it on?

The usual scientific approach to any question is first to observe and measure reality, in dimensions that seem most likely from past experience to provide a basis for disprovable hypotheses. Endorsed enthusiastically by Richard Smith, Professor Ronald Dworkin offers his "prudent insurance principle" as an innovative theory to clarify these two questions, based, he says, on five assumptions. These assumptions are not derived from any study of the real world and contradict all human experience.

He asks us to imagine a world in which wealth is justly distributed (the richest fifth of the population now gets 150 times the income of the poorest fifth, a difference that has doubled over the past 30 years); in which information is available to all on all aspects of medicine and its effectiveness (when doctors are now said to need to read 19 articles a day for $\mathbf{3 6 5}$ days a year just to keep up with internal medicine); and in which everyone makes decisions rationally, parents put their children's interests on the same level as their own, and nobody knows anything about genetic, cultural, or social predispositions to disease. Interestingly, he asks us to make two further assumptions, which are at least credible: that governments abstain from providing health care and that people would be left to make their own decisions on which insurance policies to buy, what health problems to insure against, and what intensity of treatment they should be covered for.

Dworkin is a professor of law in Oxford and New York. We are used to extraterrestrial flights of this sort from lawyers, concerned with adversarial justice rather than material truth, but his enthusiastic endorsement by Smith is serious. No refutable hypotheses can be derived from fantasies of this kind, but they lead directly to a list of social decisions that most of us have not yet learnt to accept.

JULIAN TUDOR HART

Professor

International Section,

Department of Primary Health Care,

Department of Primary Health Care,

Royal Free Hospital
London NW3 2QU

1 Smith $R$. Being creative about rationing. $B M F$

1996;312:391-2. (17 February.)

\section{Debate over NHS-wide network is centred on wrong issue}

EDITOR,-For some time the NHS and the BMA have been exchanging shots at each other about the NHS-wide network. The dispute about these technologies culminated in a heated argument after the presentation of a paper by Dr $R$ J Anderson, ${ }^{1}$ who seems to be the BMA's advocate against these technologies. Not being a partisan of either the NHS or the BMA, I wish to raise the issue that now seems to be almost forgotten-the real case for or against these technologies. Fortunately, there seems to be little dispute over the two most important points about the technologies: they entail risks with regard to security and privacy, and they could benefit patients' care substantially.

Debate might better centre on three questions. Do possible benefits to patients from the disputed technologies outweigh their possible risks? If the technologies are beneficial, are they cost effective? If the technologies are beneficia and cost effective, how can a reasonable level of risk be maintained and what is the quickest reasonable way to implementation?

My opinion is that the likely benefits to patients from these technologies outweigh their known or potential risks. Even Anderson has recognised that the NHS-wide network "might occasionally save life,"2 which seems to finish the argument conclusively in favour of the proposed technologies, given the weak risks presented.

Concerns about security and privacy are legitimate, especially with the powerful combination of the two technologies of computers and networking. The NHS has, however, considered network security carefully, and its policy ${ }^{3}$ seems at least on a par with good commercial practice. The Data Protection and Computer Misuse Acts offer effective legal recourse if security is unlawfully breached; a new European directive reinforces these acts and establishes a right to privacy. ${ }^{4}$ Unfortunately, the issue of cost effectiveness is unlikely to be resolved in the present climate. The NHS seems to be determined to proceed with implementation without inviting contributions from the public. Perhaps this is just as well, given the delays already encountered.

Raising anecdotal tales of alleged abuses of security or privacy ${ }^{12}$ or sensationalising in the press the serious issues concerning these technologies seems hardly responsible. If the argument is really over disclosure ${ }^{5}$ then why not debate that subject explicitly? The pity of this public and possibly misdirected squabble is that neither the NHS nor the BMA has been able to conduct a constructive or informed debate over technologies that could benefit patients so substantially. (n) Keele University 152 Southwark Bridge Road,

\section{London SE1 ODG}

1 Anderson RJ. Patient confidentiality-at risk from NHS-wide networking. In: Richards B, de Glanville H, eds. Current perspectives in healthcare computing. Weybridge: BJHC Books, 1996:687-92.

2 Anderson RJ. NHS-wide networking and patient confidentiality. $B M 9$ 1995;311:5-6.

3 NHS Executive. NHS-wide networking - security project: security guide for IMET specialists. London: Department of Health, 1995.

4 Smith MF. Data protection, health care, and the nev European directive. BMF 1996;312:197-8. (27 January.)

5 Anderson RJ. Clinical system security: interim guidelines. BMY 1996;312:109-11. (13 January.)

\section{Air pollution related to transport}

\section{Diesel is the main problem}

EDrroR,-David V Bates's call for new clean air legislation in Britain ${ }^{1}$ is made more urgent by the results of the two London based studies published in the same issue that show the relation between air pollution, daily mortality, and childhood wheezing. ${ }^{23}$ Ozone and particulates are most strongly related to daily mortality, ${ }^{2}$ while ozone and sulphur dioxide are most strongly related to childhood wheezing, though the study by Roger Buchdahl and colleagues did not measure particulate levels. ${ }^{3}$ Unfortunately, particulates are also carcinogenic and are the most likely explanation for the relation between air pollution and annual mortality from lung cancer. ${ }^{4}$

The main problem is diesel. Historically diesel has been perceived as an environmentally benign fuel since it is $25-30 \%$ more efficient than petrol, contains no added lead, and produces virtually no carbon monoxide. In urban areas, however, it is the main source of particulate emissions, and in London $96 \%$ of black smoke comes from 